\title{
O ENSINO DE GRAMÁTICA: REFLEXÕES E PROPOSTAS
}

\section{GRAMMAR TEACHING: CONSIDERATIONS AND PROPOSALS}

\author{
Fábio Araújo Oliveira ${ }^{1}$
}

\begin{abstract}
RESUMO
Neste trabalho, objetivamos refletir sobre o ensino de gramática nas aulas de língua portuguesa do ensino básico e apresentar propostas para a sua eficácia. Para isso, consideramos a importância tanto da reflexão linguística quanto do funcionamento da gramática no texto. Além disso, consideramos que tal ensino precisa respeitar os saberes linguísticos dos alunos e se adequar ao seu nível de escolaridade. Nesse sentido, defendemos a ideia de que a reflexão gramatical e o uso da gramática, guardadas as devidas proporções, obviamente, devem fazer parte tanto do letramento profissional do professor de língua portuguesa quanto do letramento escolar do aluno do ensino básico, já que qualquer uso linguístico envolve saberes gramaticais. Se o professor dominar o conhecimento necessário para melhor ensinar gramática, e o aluno dominar para melhor usar a gramática, conseguiremos contribuir na formação de sujeitos mais eficientes em seus usos linguísticos.
\end{abstract}

PALAVRAS-CHAVE: Gramática Tradicional. Ensino de Gramática. Letramento.

\begin{abstract}
This paper analyzes the grammar teaching in Portuguese language classes in basic education and propose outlines for its effectiveness. To do so, we consider the importance of reflecting the language and the grammar function in the text. Furthermore, we consider that education must respect the students linguistic background and adapt the to their school level. In doing so, we argue that the reflection and use of grammar, considering peculiarities, must be part of the professional literacy of the Portuguese teacher as well as the student literacy in basic education, since any linguistic use involves grammar. If the teacher masters the knowledge necessary to teach grammar, and if the learner the knowledge to use it in a more effective way, we will be able to contribute to the development of individuals more competent in their linguistic uses.
\end{abstract}

KEYWORDS: Traditional Grammar. Grammar Teaching. Literacy.

\section{INTRODUÇÃO}

O que hoje denominamos Gramática Tradicional existe há mais de 2000 anos, e a primeira obra desse tipo de Língua Portuguesa data do século XIV (OLIVEIRA, 2000) No entanto, até os dias atuais ela pode apresentar problemas de várias ordens: nas definições, nas conceituações, nas exemplificações, em sua concepção de língua, em sua ideologia etc. Tais problemas se refletem no próprio ensino de gramática na escola. O que ensinar de gramática? Como ensinar? Qual o momento certo para ensinar cada conteúdo? Essas costumam ser perguntas frequentes para os professores de língua portuguesa.

Neste trabalho, apresentamos uma reflexão sobre o ensino de gramática na escola, considerando as suas três perspectivas: a reflexão gramatical, a abordagem sobre a variação

\footnotetext{
${ }^{1}$ Fábio Araújo Oliveira é professor assistente de Linguística e Língua Portuguesa do Departamento de Ciências Humana - Campus $V$ da Universidade do Estado da Bahia - UNEB. Email: faoliveira2016@hotmail.com
} 
linguística e o funcionamento da gramática no texto. A partir dessa reflexão, propomos práticas para um ensino de gramática mais eficiente, que contribua na formação de sujeitos mais conscientes em seus usos linguísticos, tanto na modalidade oral quanto na escrita.

\section{A reflexão gramatical}

Há vários tipos de gramática. O mais antigo é a chamada gramática tradicional.

Sabe-se que a gramática, tal como a conceitua a tradição ocidental, tem origem na Grécia antiga; ela finca seus alicerces na obra de filósofos, notadamente Platão (427 a.C. - 347 a.C.) e Aristóteles (384 a.C. - 322 a.C.), que também investigaram - e buscaram explicar como se relacionam a linguagem e o mundo nomeado e convertido em conhecimento/ informação por meio de palavras (OTHERO e KENEDY (orgs.), 2015, p. 199)

Logo, a gramática tradicional (GT) possui influências da filosofia. Assim foi no seu princípio, assim é contemporaneamente também, guardadas as devidas ressalvas, é claro.

Tomemos o conceito de sujeito, por exemplo, de uma GT contemporânea: "O sujeito é o termo sobre o qual se faz uma declaração [...]" (CUNHA, 1981, p. 81). Nesse conceito, o critério para a definição do termo sintático é semântico, ou seja, privilegia o seu significado. E esse significado é construído a partir de uma lógica desenvolvida inicialmente na filosofia dos antigos gregos: declarar significa afirmar, que é o contrário de negar, e diferente de interrogar, por exemplo. outras não:

Como já sabemos hoje, esse conceito de sujeito se aplica a algumas frases, mas a

(2) A loja era o centro da vila. (CUNHA, 1981:81)

O sujeito de (2) seria a loja - e, com efeito, a frase faz uma declaração sobre ela.

Mas essa frase é apenas um exemplo; será que aquilo a que chamamos habitualmente "sujeito" sempre se conforma com essa definição? Ou seja, a definição não pode se aplicar apenas a uma frase, ou às 20 frases prediletas do autor: deve valer para todas as frases da língua. E, quando fazemos um levantamento mais amplo, surgem muitos problemas. Por exemplo, mesmo na gramática citada encontramos

(3) O menino doente era penteado pela madrinha. (Cunha, 1981:86) Essa frase faz uma declaração sobre o menino, mas também sobre a madrinha, dado que ficamos sabendo algo a respeito dela (ela penteava o menino). O que nos autoriza a dizer que o menino é que é o sujeito?

Depois, na frase

(4) A loja era o centro da vila?

a definição não nos autoriza a analisar a loja como sujeito, porque a frase não faz declaração nenhuma (é uma pergunta). (OTHERO e KENEDY (orgs), 2015, p. 187-88)

Logo, a definição de sujeito da GT, predominantemente construída com base no critério semântico e influenciada pela filosofia dos antigos gregos, falha. Assim acontece com outras definições também. 
A primeira questão que colocamos aqui em relação ao ensino de GT no ensino básico, portanto, é que os alunos devem ter acesso a uma reflexão gramatical atualizada, portanto já revisada pelo professor, ou podem analisar criticamente o instrumento que prescreve a norma padrão de sua língua materna, de acordo com o seu nível de amadurecimento na atividade de reflexão gramatical. Desde o ensino fundamental II já é possível considerar no ensino de língua a análise crítica da GT, associada à reflexão sobre o uso da língua. A partir do $8^{\circ}$. ano, acreditamos que isso já deve fazer parte do seu letramento escolar.

A expressão letramento escolar refere-se aos usos, às práticas e aos significados da língua escrita no contexto escolar. Tal designação decorre da compreensão de que o letramento varia de acordo com o contexto em que ocorrem eventos de letramento. Ler e escrever na escola são processos que se diferenciam de ler e escrever fora da escola, pois o quê, como, quando, para que se lê ou se escreve na escola são aspectos definidos a partir das especificidades dessa instituição, que visa, em última instância, ao ensino e à aprendizagem. A expressão letramento escolar, portanto, aponta para as diferenças entre práticas de leitura e escrita desenvolvidas dentro e fora da escola (GLOSSÁRIO CEALE, 2017)

Se estamos defendendo que o estudante do ensino fundamental pode e/ou deve analisar criticamente a GT de sua língua materna, dependendo do seu ano de escolaridade, no caso do professor de português isso passa a ser uma obrigação maior e deve fazer parte do seu letramento profissional, ou seja, do seu letramento como professor de língua.

Em grande parte, a crítica feita à GT vem dos estudos produzidos pela Linguística desde o surgimento dessa ciência. Foi ela que problematizou a GT, em um primeiro momento, através de análises da língua em vários níveis, como se pode observar nas pesquisas feitas em Morfologia, Sintaxe, Fonologia e Semântica, bem como por meio de estudos linguísticos mais contemporâneos, em um segundo momento, como os feitos pela sociolinguística sobre variação e mudança linguística, por exemplo, ou feitos pelas teorias do sentido que extrapolaram os limites da sentença, como a pragmática, a linguística textual e a análise do discurso.

O professor de língua, tendo acesso inclusive a todo esse conhecimento linguístico, deve mediar, de forma consciente e madura, a reflexão linguística do aluno, considerando as especificidades de cada turma. Dessa forma, há dois caminhos, dependendo do nível de escolaridade do aluno: ou o conteúdo gramatical já é apresentado ao aluno com os avanços filtrados pelo professor, ou o professor faz a mediação da análise crítica que o aluno vai fazer.

Em relação ao sujeito, por exemplo, com uma análise mais cuidadosa, considerando os usos da língua e a produção de conhecimento que hoje temos sobre o assunto, bem como uma análise crítica da GT, o professor tem condições de considerar que o sujeito, a partir de suas diversas realizações, é o termo que, como podemos verificar em AZEREDO, 1990; OTHERO e KENEDY (orgs.), 2015; SOUZA e SILVA, KOCH, 1996:

a. É um constituinte sintático, ou seja, um sintagma;

b. Pode ser explícito (realizado lexicalmente) ou não;

c. É um sintagma nominal, ou seja, é um constituinte que possui como núcleo um NOME, um PRONOME, ou uma palavra "substantivada";

d. Pode anteceder o verbo ou ser posposto a ele, identificando uma marca de ordem direta ou indireta na constituição da sentença; 
e. Possui uma forma padrão de constituição, conforme regras da gramática tradicional, mas possui variantes, considerando o uso da língua;

f. Liga-se ao verbo da sentença a que pertence, concordando com ele em número e pessoa na norma padrão; na norma culta ou não-padrão, essa ligação não obedece necessariamente a tal concordância;

g. Pode ser: topicalizado, clivado, deslocado, passivizado e pronominalizado;

h. Possui alguns papeis semânticos, dependendo do verbo a que se liga;

i. É definido considerando o tipo de frase a que pertence. Assim, em frases declarativas, é o termo sobre o qual se afirma alguma coisa. Em frases interrogativas, é o termo sobre o qual se interroga alguma coisa etc;

j. Pode ser encontrado fazendo-se a pergunta "Quem?" ou "O quê?" ao verbo a que o sujeito se liga, seguindo o esquema: "pronome + verbo +?".

1. Possui função no texto em que está inserido, contribuindo na construção do sentido do texto;

m. Pode marcar posições de sujeito no discurso etc.

Como se vê, para a identificação de um termo sintático, e também para compreender o seu funcionamento em textos, devemos recorrer a diversos critérios, como o morfossintático, o semântico, o textual, o pragmático e o discursivo. Assim, informações variadas sobre o sujeito podem ser acionadas para a identificação desse termo sintático em um texto. Tais informações decorrem também de um olhar crítico em relação à GT. O professor precisa tê-las para melhor orientar o aluno, adequando e adaptando o conteúdo a eles.

Para a compreensão do texto abaixo, que um aluno de ensino fundamental II já deve ter condição plena de interpretar, precisamos entender o funcionamento do sujeito, ou empiricamente, ou recorrendo ao que sabemos sobre ele; quanto mais soubermos, melhor. Vejamos como os autores da gramática pedagógica que traz o texto (CEREJA e MAGALHÃES, 2016, p.332) elaboram questões a fim de que o aluno compreenda a tirinha e reflita sobre a noção de "oração sem sujeito", inclusive fazendo uso da nomenclatura gramatical: 


\section{Oração sem sujeito}

\section{CONSTRUINDO O CONCEITO}

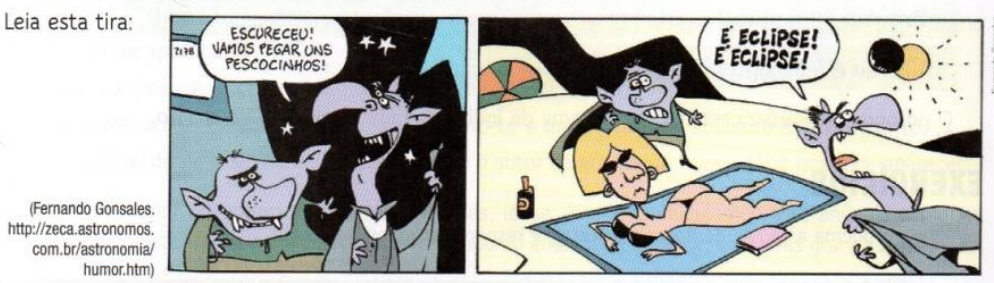

1. Quando veem o céu escuro, os vampiros resolvem sair.

a) A quem se refere a forma verbal vamos pegar em "Vamos pegar uns pescocinhos", ou seja, qual é o sujeito dessa forma verbal? Como se classifica o sujeito dessa oração?

b) Que relação há, na tira, entre o fato de escurecer e a saída dos vampiros para "pegar uns pescocinhos"?

2. Observe os predicados:

\section{"Escureceu!" \\ "É eclipse!"}

Esses predicados se referem a um sujeito mencionado anteriormente?

3. Compare estas duas orações:

Agora o céu ficou escuro. Agora escureceu.

a) Em qual dessas oraçōes o predicado se refere a um sujeito simples? Qual é esse sujeito?

b) Em qual o predicado não se refere a um ser especificamente, apenas faz uma indicação a respeito do tempo?

4. O humor da tira está no último quadrinho, quando um dos vampiros diz: "É eclipse! É eclipse!".

a) Explique qual é o mal-entendido que gera o humor da tira.

b) Qual é o sujeito da oração "É eclipse!"?

\section{CONCEITUANDO}

Ao responder às questões anteriores, você pôde constatar que, na língua portuguesa, hâ orações em que a declaração expressa pelo predicado não pode ser atribuída a nenhum ser: "Escureceu!", "É eclipse!". Esse tipo de oração é chamado de oração sem sujeito.

\footnotetext{
Nesse tipo de oração, o verbo é impessoal.

$$
\begin{gathered}
\text { Oração sem sujeito é aquela em que a declaração expressa pelo } \\
\text { predicado não é atribuída a nenhum ser. }
\end{gathered}
$$

UNIDADE 4 CAPÍTULO 25
}

Imagem 1: Oração sem sujeito. Abordagem de conteúdo gramatical em gramática escolar.

$\mathrm{Na}$ questão 1, a pergunta "a quem se refere a forma verbal 'vamos pegar' em 'Vamos pegar uns pescocinhos', ou seja, qual é o sujeito dessa forma verbal?” é uma pergunta atualizada em relação aos estudos sintáticos. Ela parte do verbo, entendendo-o como um predicador, e faz uma pergunta específica a ele para encontrar o seu argumento externo, ou seja, o seu sujeito. E compreender o sujeito é importante para a compreensão do texto.

Ao contrário do que costumam fazer as descrições tradicionais, que sempre iniciam as lições de análise sintática pelo "sujeito", comecemos nossa reflexão pelo "predicado". Por que será que a gramática tradicional (GT) classifica os predicados em "verbais", "nominais" e "verbo-nominais"? É justamente porque neles se encontram os elementos que projetam os constituintes centrais da oração, incluindo o próprio sujeito. A esses elementos chamamos "predicadores", que são responsáveis pela estrutura principal da oração. 
Esses predicadores selecionam normalmente um argumento externo (a que chamamos sujeito) e, opcionalmente, argumentos internos (a que chamamos complementos). Todas as vezes que tentamos identificar os termos de uma oração que contenha um predicado verbal, como, por exemplo, "oferecer", e perguntamos: "quem oferece", "oferece o quê?”, "oferece a quem?", ou dizemos "alguém oferece alguma coisa a alguém", estamos, na verdade, observando a estrutura projetada pelo predicador ou, em outras palavras, estamos buscando entender qual é a seleção semântica que esse predicador faz. (DUARTE In: VIEIRA e BRANDÃO (orgs), 2013, p. 198)

$\mathrm{Na}$ questão 2, a pergunta "Esses predicados se referem a um sujeito mencionado anteriormente" possibilita o aluno refletir sobre a ausência do sujeito, ou seja, sobre a ausência de uma referência linguística para os núcleos das sentenças, que sabemos que são os predicadores "escureceu" e "eclipse".

$\mathrm{Na}$ questão 3, a comparação feita é importante para compreender que, a depender da forma como produzimos o texto, sentidos diferentes são produzidos. No caso, é o sujeito que está em foco.

Ao conceituar "a oração sem sujeito", a gramática pedagógica acertadamente aproveitou o conhecimento construído anteriormente pelo aluno sobre o assunto, a partir das questões de interpretação de texto e de gramática funcionando no texto. Entretanto, falhou em não fazer uma reflexão crítica sobre a própria noção, que se mostra incoerente.

$\mathrm{Na}$ atividade da gramática pedagógica apresentada a seguir (CEREJA e MAGALHÃES, 2016, p. 307), a reflexão sobre o sujeito que o aluno é levado a fazer não só o ajuda na interpretação do texto, como contribui para que ele escreva melhor, à medida que se compreende o papel do sujeito na concordância verbal, na norma padrão: 


\section{O SUJEITO E O PREDICADO \\ NA CONSTRUÇÃO DO TEXTO}

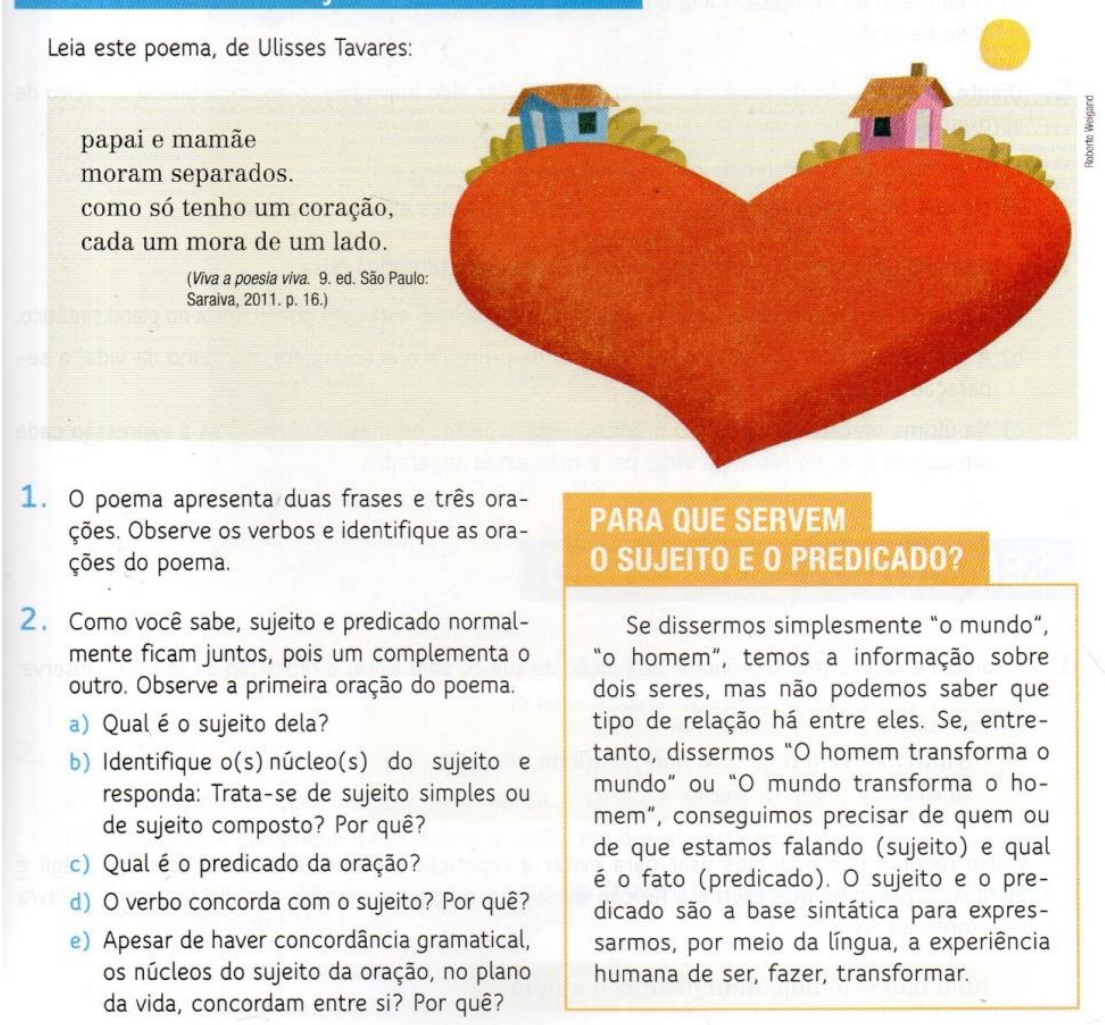

Imagem 2: O sujeito e o predicado na construção do texto. Abordagem de conteúdo gramatical em gramática escolar.

MORFOSSINTAXE: A SELEÇÃO E A COMBINAÇÃO DAS PALAVRAS

Aqui, precisamos lembrar que o papel da GT no ensino básico é contribuir para que alunos usem a língua com propriedade e autonomia, considerando os contextos de uso. Assim, em relação ao sujeito, por exemplo, o mais importante é que os alunos analisem o seu funcionamento em textos e saibam utilizá-los corretamente em suas produções textuais. Entretanto, a identificação e reconhecimento do termo pode e deve ajudá-los em seus usos linguísticos. Ou seja, o uso não deve ser só empírico, através da incorporação inconsciente das formas linguísticas; deve ser também reflexivo, considerando norma linguística, sujeitos, gêneros textuais, espaços de produção, enfim, considerando os contextos.

Nessa perspectiva, a categorização na língua, como a de classes de palavras e funções sintáticas, por exemplo, resulta numa economia interessante na reflexão linguística, reduzindo a demanda da memória humana, facilitando o armazenamento e a recuperação da informação.

\section{Gramática e variação linguística}

Voltando à história da gramática tradicional, no princípio ela concentrou-se na análise literária de grandes poetas e autores dramáticos gregos, produzindo uma norma padrão que era confundida com a própria língua e excluindo a diversidade de usos distintos de tal norma.

Estava preparado o terreno para o surgimento da gramática como conjunto de conceitos sobre a língua e como disciplina pedagógica. O coroamento desse percurso do pensamento grego foi a elaboração de tékne grammatiké (Arte de escrever) de Dionísio, o Trácio, membro da comunidade intelectual da colônia grega de Alexandria, 
no século II a.C. Essa obra assinala a instituição da língua como objeto autônomo de um novo campo de reflexão e análise, com objetivos próprios. (OTHERO e KENEDY (orgs), 2015, p. 199)

Logo, considerando o seu valor simbólico e o seu caráter pedagógico, a GT funda, no ocidente, até onde sabemos, o discurso do falar e escrever corretamente, favorecendo, ao longo de sua existência, as classes privilegiadas econômica e socialmente, por terem acesso a boas escolas, onde normalmente se ensina com qualidade a norma padrão, baseada nos considerados bons escritores da língua em estudo, como vimos.

Tivemos que aguardar o século XX e a força da revolucionária corrente linguística chamada Sociolinguística para, de fato, começarmos a "abrir os olhos" sobre a questão do preconceito linguístico, instituído e mantido pela GT ao longo dos séculos, e por todas as práticas de poder que mantiveram quase que inalterado o valor da GT.

Assim, a segunda questão que colocamos aqui, em relação ao ensino de GT no nível básico, é que a língua é diversa, logo o estudo da norma padrão de uma língua não pode silenciar a reflexão sobre essa condição de qualquer língua: as suas diferenças dentro da sua unidade. A diversidade da língua precisa ser abordada e analisada na escola, como forma de compreender o papel do ideológico na significação da língua e de suas normas e, com isso, buscar instrumentalizar o aluno para o conhecimento crítico a respeito de seu idioma.

Sabemos que a diversidade linguística vem sendo historicamente significada positiva ou negativamente, de acordo com as relações de poder a que está submetida:

Falantes de qualquer língua prestigiam ou marginalizam certas variantes regionais (ou pelo menos não as discriminam), a partir da maneira pela qual as sequências sonoras são pronunciadas. Assim, determinamos variantes de prestígio e variantes estigmatizadas. Algumas variantes podem ser consideradas neutras do ponto de vista de prestígio. Temos em qualquer língua as chamadas variantes padrão e variantes não padrão. Os princípios que regulam as propriedades das variantes padrão e não padrão geralmente extrapolam critérios puramente linguísticos. (SILVA, 2013, p. 12)

Como a língua não deve ser vista apenas do ponto de vista puramente formal, como um sistema, e mais especificamente como um sistema autônomo, mas também deve ser compreendida pelo seu caráter social, histórico e ideológico, acreditamos que o que há não é somente variação, mas também hierarquização.

Isto me leva a dizer que, do ponto de vista que aqui assumo, uma língua não é variável, no sentido em que esta noção é tomada pela sociolinguística quantitativa.

Para mim uma língua é dividida, de tal modo que ela é uma e é diferente disso. (...)

E esta divisão é marcada por uma hierarquia de identidades. Ou seja, esta divisão distribui desigualmente os falantes segundo os valores próprios desta hierarquia. E aqui pode-se ver como a Escola, entre outras instituições e instrumentos, é fundamental na configuração do espaço enunciativo de uma língua nacional, no nosso caso o Português.

E estar identificado pela divisão da língua é estar destinado, por uma deontologia global da língua, a poder dizer certas coisas e não 
outras, a poder falar de certos lugares de locutor e não de outros, a ter certos interlocutores e não outros. (GUIMARÃES, 2005, p. 21)

Nessa perspectiva, cabe à educação básica garantir ao aluno que ele conheça, analise e reflita criticamente sobre a diversidade da língua, bem como sobre o papel do ideológico na construção de uma hierarquização das variantes linguísticas, tanto na oralidade quanto na escrita.

O ponto de partida para essas reflexões deve ser a própria linguagem do aluno, ou seja, a sua variedade linguística. Diante da produção linguística do aluno, sobretudo na oralidade, professor terá como ajudá-lo a identificar as regras próprias da variedade que utiliza, para, posteriormente, ajudá-lo a se conscientizar das diferenças existentes entre essas regras e as regras da variedade padrão. Mas é importante que as intervenções do professor sejam feitas de tal forma que respeitem e valorizem o saber do aluno. (MARINHO e COSTA VAL, 2006, p 39)

É importante lembrar que qualquer norma da língua possui regras internas, porque obedece a uma estrutura específica que comanda a organização dos itens linguísticos. Também é importante lembrar que os usos linguísticos possuem regras externas, porque eles precisam ser coerentes à sua situação comunicativa.

As diferenças gramaticais entre as diversas variedades também devem ser trabalhadas na escola. No estudo da variedade padrão formal, podem ser apontadas construções que divergem das usadas noutras variedades. Algumas delas, facilmente identificáveis, dizem respeito à formação das orações relativas (que a gramática tradicional chama de orações adjetivas), ao emprego dos pronomes usados como objeto direto, às regências de alguns verbos, às concordâncias, ao emprego de formas verbais do subjuntivo. Algumas formas diferentes do padrão são exemplificadas nos itens a seguir:

a) A princesa que o poeta casou com ela era bonita.

b) No ano que eu nasci o Brasil foi campeão.

c) No recreio a menina chamou ele para brincar.

d) Você me empresta a bola e eu te ponho no meu time.

e) Ele foi na vila buscar dinheiro.

f) Os carro que trazia os jogador já chegaram.

g) Se ele trazer o som vai ter a maior festa.

Para lidar com as diferenças entre a variedade padrão formal e as variedades dialetais dos alunos, é preciso que o professor conheça essas variedades, de modo a reconhecer os recursos linguísticocomunicativos de que os alunos dispõem e mostrar-lhes que, para o bom desempenho em certas atividades, em certas situações, deverão utilizar outros recursos e seguir outras regras: as do padrão formal da língua. (MARINHO e COSTA VAL, 2006, p. 43)

O trabalho com a variação linguística nas aulas de língua portuguesa deve acontecer em todo o ensino básico; em cada etapa, obviamente, deve-se considerar o conhecimento prévio dos alunos, o nível em que estão e as possibilidades que a escola oferece para isso. 
Esse trabalho também deve compreender a prática da oralidade, da produção escrita, da reflexão gramatical e da leitura, literária ou não.

\section{A gramática funcionando no texto}

Desde a década de 1980, no Brasil, sob forte influência da Linguística Textual e do sociointeracionismo, a produção acadêmica sobre ensino de língua, principalmente na área de Linguística Aplicada, vem nos mostrando a importância de abandonar um ensino gramaticista, focado na análise gramatical descontextualizada, a partir de frases selecionadas ou produzidas apenas para a exemplificação da regra gramatical, como no exemplo a seguir: Exercício 6:

(PUC-SP) Identifique a alternativa que contém uma oração sem sujeito:
A)
Ontem fez muito calor.

B) Vive-se bem em apartamentos.

C) Existem muitos apartamentos à venda.

D) $\quad$ dia de ontem foi muito quente.

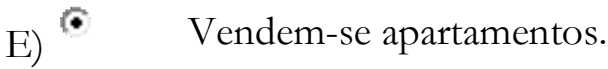

(Revista Infoescola, 2019)

Com base em tudo que dissemos até agora e nesse exemplo de atividade sobre o sujeito, que deve ser evitada, pontuamos aqui mais uma questão, que é central no ensino de língua: o foco desse ensino é a própria língua em uso nos processos interacionais, e isso acontece através de textos. Assim, o professor de língua precisa ter instrumentos suficientes para trabalhar a gramática funcionando no texto, nos diversos textos, ou seja, precisa saber trabalhar a importância dos itens gramaticais na/para construção de textos, tanto de autores consagrados, quanto de alunos autores e outros escritores. Como consequência de tal abordagem, o aluno deverá refletir sobre gramática primordialmente para interpretar textos orais ou escritos e produzi-los, e não para provar ao professor que sabe teoria gramatical.

Observemos o texto a seguir:

\section{LUTO}

LUTO.

EU LUTO?

NÃO LUTO.

NÃO, LUTO!

LUTO, NÃO!

EU, LUTO SIM!

NÃO, LUTO NÃO!

(OLIVEIRA, 2016, p. 17)

Para interpretar esse texto, o leitor precisa: 
a) Conhecer o seu gênero, um poema, e tudo o que ele implica: a busca por uma linguagem mais criativa, a organização do texto em versos e estrofe, os deslocamentos de sentido, a linguagem sintética etc.

b) Conhecer o vocabulário e as relações entre as palavras.

c) Compreender a coesão e a coerência do texto, ou seja, como ele está concatenado e de que forma é construída a sua unidade de sentido.

d) Considerar as condições de produção do texto, o que envolve saber: quem escreve, para quem escreve, o contexto situacional e os pré-construídos que atuam na significação do texto.

e) Considerar a norma linguística em que o texto foi escrito, e nesse caso é a norma padrão.

f) E compreender como a gramática funciona nesse texto; isso é fundamental.

Nesse poema, há um jogo de sentidos com a palavra "luto", que é o próprio título do texto. No contexto específico, luto pode significar:

luto

lu·to

sm

1 Sentimento de pesar ou tristeza pela morte de alguém; burel, cipreste.

2 Tristeza profunda causada por grande calamidade; dor, mágoa, aflição.

3 Panos pretos com que se forram a câmara ardente, a casa ou a igreja por ocasião do falecimento de uma pessoa.

4 Vestes escuras que a família e amigos da pessoa falecida usam durante certo tempo, como sinal do seu pesar ou tristeza.

5 Tempo que dura o uso dessas roupas.

$6 \mathrm{O}$ aspecto tristonho das coisas.

(MICHAELIS, 2019a)

Com esse sentido da palavra "luto", temos um processo de designação, de substantivização, ou seja, a palavra dá nome a um sentimento, a um comportamento ou a uma prática. $\mathrm{Na}$ gramática tradicional, estaríamos falando de uma classe gramatical específica: o substantivo. $O$ aluno precisa entender como essa palavra funciona no texto, mesmo que não utilize a nomenclatura específica para isso. É importante lembrar que, nos anos iniciais do ensino fundamental, é possível ensinar gramática sem necessariamente ensinar regras e nomenclatura.

Mas há um outro sentido para a palavra "luto" no texto; o sentido de lutar. No dicionário, esse vocábulo pode significar:

lutar

lu·tar

vti e vint

1 Enfrentar alguém, corpo a corpo, com ou sem arma; testilhar: Lutou com o colega da escola por uma coisa sem a menor importância. Meus dois priminhos lutavam o tempo todo.

vti e vint

2 Travar luta ou engajar-se em combate ou batalha, com o objetivo de vencer o inimigo: Meu tio lutou contra os fascistas na Itália. Nas Forças Armadas, os soldados são preparados para lutar. 


\section{vtd e vint}

(...)

4 FIG Opor-se fortemente a alguma coisa que se considera nociva, negativa ou injusta: Há várias entidades que lutam contra o racismo.

\section{vti e vint}

5 FIG Despender força e energia, trabalhar com afinco para conseguir determinado fim: É um político sério, que sempre lutou por seus ideais. Sem lutar, não saberá quanto vale uma vitória.

\section{vti e vint}

6 Olhar de frente, sem demonstrar covardia ou fraqueza; arrostar, encarar, enfrentar: Minha família lutou com dificuldades a vida inteira. Ela é uma pessoa corajosa e determinada; se acredita em algo, luta sempre.

(...)

(MICHAELIS, 2019b)

O outro sentido da palavra "luto" no poema diz respeito a um processo de verbalização, porque faz referência à ação de lutar. O dicionário MICHAELIS elencou vários conceitos para essa palavra e acabamos de mostrar alguns deles, mas nenhum se aplica plenamente ao sentido de "lutar" no poema em questão, apenas se aproxima. No poema, "lutar" significa resistir à tristeza, à dor de uma perda.

O jogo de sentidos da palavra "luto" no poema não se resume ao fato desse vocábulo ser em um momento substantivo e em outro verbo. Vai além disso. O texto joga com a ambiguidade. O título, por exemplo, pode ser uma coisa ou outra, ou as duas simultaneamente. No decorrer do poema, há possibilidade de em alguns momentos o leitor escolher que sentido faz mais sentido. Em outros momentos, a própria construção sintática define que classe gramatical está sendo empregada.

Mas como orientar o aluno para essa interpretação? Pensamos nas seguintes questões que envolvem a gramática funcionando no texto e uma reflexão gramatical também. As questões foram pensadas para turmas dos anos finais do ensino fundamental.

1. Quais os sentidos da palavra "luto" no poema?

2. A que classes de palavras cada sentido pertence?

3. É possível definir com certeza, em cada emprego da palavra "luto", a que classe a palavra pertence?

4. Há ambiguidade no texto? Explique.

5. Considerando a classe gramatical, como funciona o emprego da palavra "luto" no texto?

Outra questão a ser trabalhada em relação à gramática é como contribuir para que o aluno diferencie um substantivo de um verbo, já que isso é importante para compreender o funcionamento da palavra "luto" no poema. Aqui, o professor pode recorrer também a critérios sintáticos e morfológicos para estabelecer a diferença. Assim, o substantivo é a palavra que pode funcionar como núcleo do sintagma nominal e ser determinada por um artigo, um pronome adjetivo, um numeral etc., ou seja, por um determinante, e pode ser modificada por um adjetivo, uma locução adjetiva etc, ou seja, por um modificador. Além disso, o substantivo pode se flexionar em gênero e número. Com o verbo é diferente; ele pede um argumento externo, que é o sujeito, e pode pedir um argumento interno, que é um complemento. O verbo funciona como núcleo do sintagma verbal e pode ter um complemento circunstancial ligado a ele. Além disso, flexiona-se em número e pessoa, tempo e modo, e aspecto, por exemplo. Esse conhecimento sintetizado pode ser utilizado pelo professor para elaborar questões como essas: 
1. No poema, em algum emprego da palavra "luto" este vocábulo está relacionado a um sujeito? Identifique!

2. Em um texto, que classe de palavra pode pedir um sujeito?

3. No poema, quando a palavra "luto" aparece como verbo, em que número, pessoa, tempo e modo o vocábulo está?

4. Que classe de palavra se flexiona em número e pessoa, tempo e modo?

5. No poema, em algum emprego da palavra "luto" este vocábulo pode ser determinado por um artigo?

6. Em um texto, que classe de palavra pode ser determinada por um artigo?

7. No poema, quando a palavra "luto" aparece como substantivo, é uma palavra masculina ou feminina? Está no singular ou no plural?

8. Considerando as suas respostas anteriores, que diferenças há entre verbo e substantivo?

Por fim, lembramos mais uma vez que, nos anos iniciais do ensino fundamental, a gramática não precisa ser apresentada de forma explícita, com sua vasta nomenclatura, definições e regras.

\section{CONCLUSÃO}

Há três caminhos importantes para se trabalhar a gramática na escola: o da reflexão gramatical, o da variação linguística e o do funcionamento da gramática no texto. São caminhos que se complementam e estão interligados, e só os separamos aqui por questões metodológicas. Uma das grandes dificuldades dos professores de língua portuguesa é justamente fazer essa articulação entre esses percursos.

Outra grande dificuldade desses professores é adequar o ensino de gramática, com toda sua complexidade e abrangência, ao nível escolar do aluno. Para isso, é preciso considerar o contexto e tudo o que ele envolve. Assim, o ensino de gramática não deve ser o mesmo em diferentes níveis de escolaridade, mesmo que o assunto gramatical trabalhado o seja.

Além dessas dificuldades, há uma terceira, e talvez essa seja o grande fantasma ainda hoje no ensino de língua: como ensinar a gramática funcionando no texto. Parece que nem os livros, nem os cursos de licenciatura em Letras têm trabalhado satisfatoriamente essa questão.

Com este artigo, esperamos ter contribuído com o professor de língua portuguesa em relação à sua reflexão sobre o ensino de gramática, o que, como defendemos, deve fazer parte de seu letramento profissional. Essa é uma condição essencial para que esse professor tenha possibilidades de orientar com eficácia o aluno em suas aprendizagens e usos da gramática. Como vimos, o ensino de gramática é um universo complexo e com práticas diversas. Que saibamos transitar nesse espaço!

\section{Referências bibliográficas}

AZEREDO, J. C. Iniciação à sintaxe do português. Rio de Janeiro: Jorge Zahar, 1990.

CEREJA, W. R. e MAGALHÃES, T. C. Gramática: texto, reflexão e uso. $5^{a}$ ed. São Paulo: Atual, 2016.

CUNHA, C. Gramática de base. Rio de Janeiro: Ministério da Educação e Cultura/ Fundação Nacional de Material Escolar, 1981. 
GLOSSÁRIO CEALE - Termos de alfabetização, leitura e escrita. http://ceale.fae.ufmg.br/app/webroot/glossarioceale/verbetes/letramento-escolar Acessado em 10 de jun. de 2019

GUIMARÃES, E. Semântica do acontecimento: um estudo enunciativo. 2a . ed Campinas, SP: Pontes, 2005.

MARINHO, J. H. C. e COSTA VAL, M. da G. Variação linguística e ensino: caderno do professor. Belo Horizonte: Ceale, 2006. 60 p. (Coleção Alfabetização e Letramento).

MICHAELIS. Dicionário Brasileiro da Língua Portuguesa. http://michaelis.uol.com.br/busca?id=PqXBG, acessado em 30 de maio de 2019a.

MICHAELIS. Dicionário Brasileiro da Língua Portuguesa http: $/ /$ michaelis.uol.com.br/busca? $\mathrm{r}=0 \& \mathrm{f}=0 \& \mathrm{t}=0 \&$ palavra $=$ lutar , acessado em 30 de maio de $2019 \mathrm{~b}$.

OLIVEIRA, F. A Gramática da Linguagem Portuguesa. Edição crítica, semidiplomática e anastátia. Organização de Amadeus Torres e Carlos Assunção, com estudo introdutório de Eugenio Coseriu. Lisboa: Academia de Ciências de Lisboa, 2000.

OLIVEIRA. F. Caminhos. Londrina (PR): Editora Madrepérola, 2016.

OTHERO, G. de A. e KENEDY, E. (orgs.) Sintaxe, sintaxes: uma introdução. São Paulo: Contexto, 2015.

Revista InfoEscola. $\quad$ Exercícios $\quad-\quad$ Sujeito. https://www.infoescola.com/portugues/sujeito/exercicios/, acessado em 29 de maio de 2019

SILVA, T. C. Fonética e Fonologia do Português. 10ª ed São Paulo: Contexto, DUARTE. M. E. Termos da oração In: VIEIRA, S. R., BRANDÃO, S. F. Ensino de gramática: descrição e uso. $2^{a}$ ed. $2^{a}$ reimpressão. São Paulo: Contexto, 2013.

SOUZA e SILVA, M. C. P. de; KOCK, I. V.ed. Linguística aplicada ao português: sintaxe. $7^{\mathrm{a}}$ ed. São Paulo: Cortez, 1996.

Submetido em 12/06/2019

Aceito em 16/07/2019

Publicado em 05/08/2019 